\title{
The Analysis of Rural E-commerce In Qingyanliu Pattern
}

\author{
Jing Zhang \\ Department of Management Science and Engineering, Beijing Forestry University, Beijing, 100083, China
}

Keywords: Rural areas, E-commerce, Qingyanliu pattern, Yiwu.

\begin{abstract}
Nowadays, with the rapid development of rural e-commerce. The Qingyanliu Village of Yiwu City, Zhejiang Province, with its huge flow of people, information flow and a strong entrepreneurial atmosphere, was praised by the Premier Li Keqiang as "deserves to be the first village shop". It has become a model of rural electric business development. Corresponding to the "Qingyanliu pattern" is also emulated around. This paper focus on the "Qingyanliu pattern", through field research, data collection, visiting to local stakeholders and other means, analyzes the basic situation and advantages of "Qingyanliu pattern", analyzes its main problems and puts forward relevant suggestions.
\end{abstract}

\section{Qingyan Liu model of the basic overview of rural electricity business}

Qingyan Liu Village is located in Jiangdong Street, Yiwu City, Zhejiang Province. Because of its low cost of living in urban and rural areas, the housing structure of the old village is suitable for accommodation, office and warehousing. In addition, Yiwu itself has a large amount of commercial information, convenient logistics channels, rich commodity resources and other advantages, greatly reducing the threshold of Qingyan Liu village venture, so that Qingyan Liucun is suitable for the beginning of the grass-roots business to start business. Qingyan Liu Village's electric business era began in September 2007 when a company called affordable shop Taobao shop was opened to make it possible for the little-known small village to brew its own brilliance.

Qingyan Liu model is to rely on the current popular Internet plus form, combined with urban and rural resources, and integrate multi-element and multi-industry in order to achieve traditional industry Internet, trade commercialization and rural urbanization in response to the call of public entrepreneurship and innovation issued by Prime Minister Li Keqiang.

Qingyan Liu model's features can be summarized as follows: multi-regional integration, multi-factor support, multi-industry as the driver force. Among them, multi-area refers to the city, rural and regional as well as outside areas; multi-factor mainly includes information, land, network and entrepreneurial personnel; multi-industry mainly includes the traditional manufacturing industry, business services and logistics and express delivery industry. Among them, the city provides the living facilities, the village reduces the threshold of entrepreneurship, the region inside and outside has brought entrepreneurial flow and business flow, and more elements are as a venture to support the infrastructure, multi-industry is to guarantee for all aspects of electricity and the Internet will integrate them all together, thus forming a unique Qingyan Liu model. 


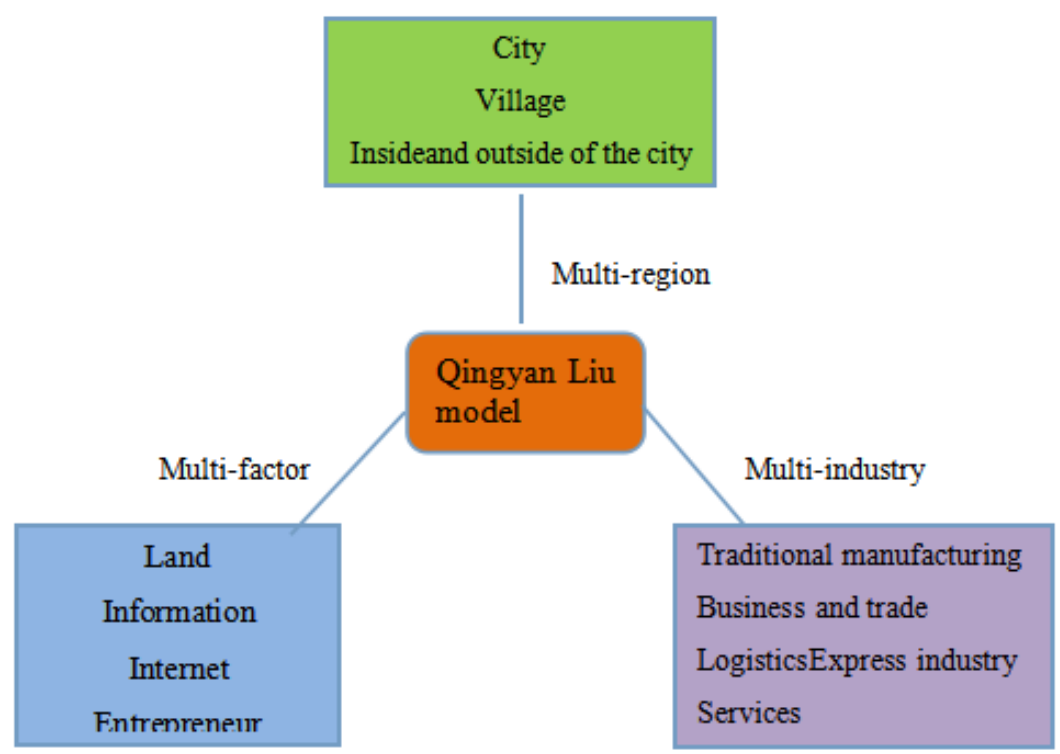

Fig. 1. Qingyan Liu model

\section{The Qingyan Liu model development and advantages}

\section{Qingyan Liu model development process and the status quo}

The past decade has witnesses the rapid development of the electricity industry, Qingyan Liu village has developed from the first ordinary small village into a shop first village praised by Premier Li Keqiang, after a long process of exploring from 2008 to 2009. During the period, some villagers began to start a business of Taobao shop with the commodity market as the supply ; In 2010, Source sharing, technology sharing, capital sharing model is promoted to help network operators to solve such issues as capital, sourcing and technology; After 2011, NET goods supermarket model, commonly know as Small mixed Batch, began to pilot where the network merchants purchase from the Yiwu international Trade City wholesale, or directly goes to the factory to place orders. They will sell the goods with the relatively low price wholesale to Taobao merchants, so that the network of suppliers and other problems have been effectively resolved.

According to statistics, there are nearly 20,000 people from all over the country engaged in network sales and other related industries that are gathered in the Qingyan Liu. More than 4,000 registered online stores around the world sell all kinds of products up to 10 million pieces every day. In recent years, Qingyan Liu Village, the total sales of electricity and the number of registered online stores are increasing.

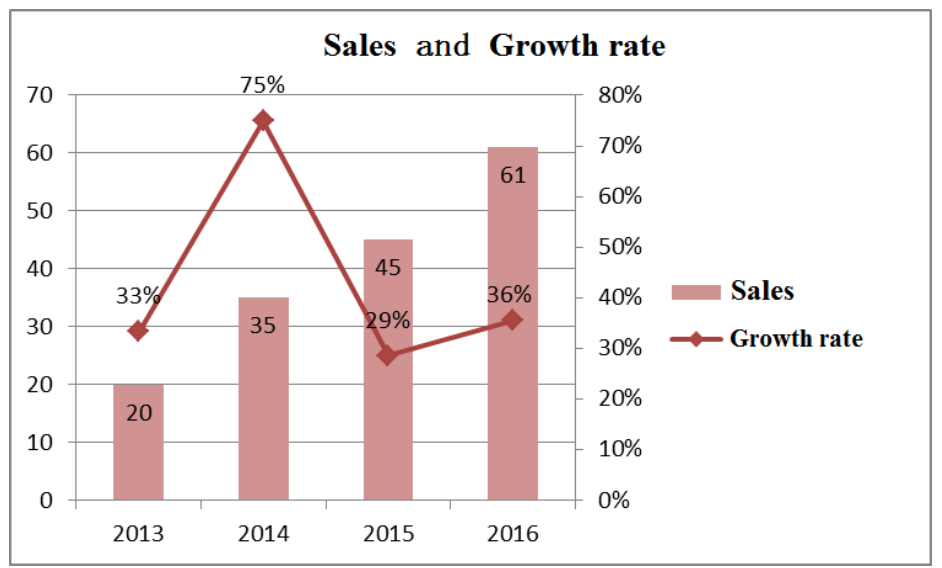

Fig. 2. 2013 - 2016 Qingyan Liu Village, the total sales of electricity 


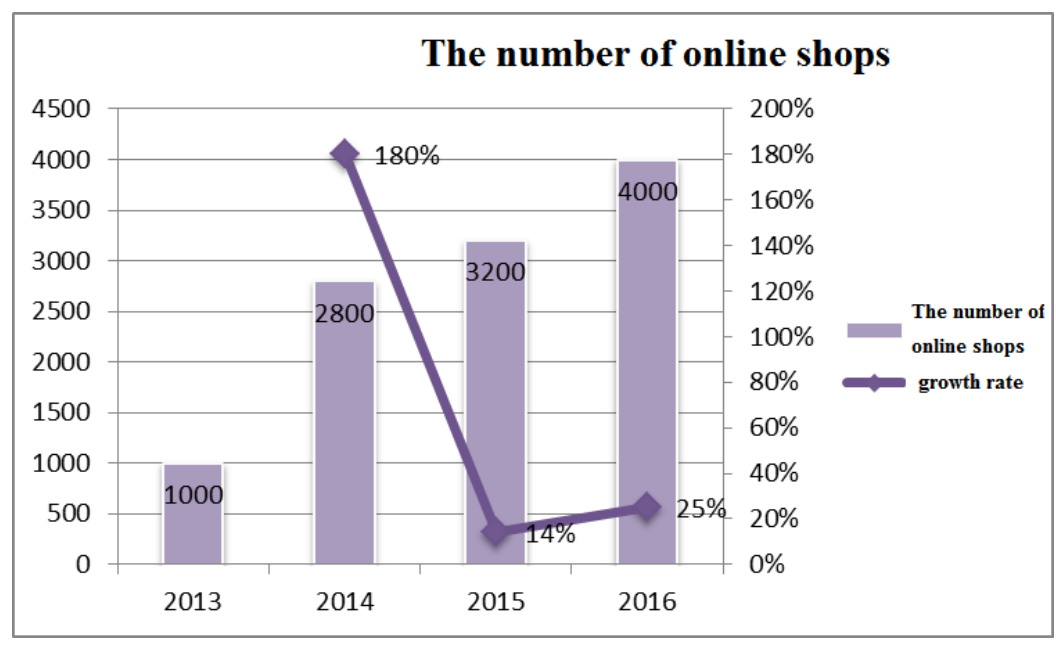

Fig. 3. 2013 - 2016 Qingyan Liu Village shop number

According to Yiwu City Bureau of Statistics released by the 2016 Yiwu City of electricity business professional village, the total sales of electricity and the number of online stores are increasing year by year from 2013 to 2016 in Qingyan Liu Village, of which 2014 witnessed the most rapid growth over the previous year. From the point of view of total sales of electricity, in Qingyan Liu Village, electricity sales were 2.0 billion yuan, 3.5 billion yuan, 4.5 billion yuan, 6.1 billion yuan, respectively from 2013 to 2016, an increase of 33\%, $75 \%$, 29\%, 36\% over the previous year. In view of the number of online stores, there are about 1000 in 2013, 2014 to 2,800, up 180\% over last year, 2015 to 3200, up 14\% over last year, 2016 to 4000 , up 25\% over last year.

\section{Qingyan Liu model advantages}

Qingyan Liu model owes its success to besides the spirits of locals dare to think, dare to try, dare to fight its environment and the advantages of all aspects of the conditions which can not afford to be ignored, I summarized them as follows:

Complete facilities

In terms of infrastructure, Qingyan Liu has achieved 100\% free fiber access, public places free Wifi full coverage which provides a solid foundation. In terms of hardware for the development of e-commerce. In hardware, Qingyan Liu has a low rent cheap with the housing structure suitable for villagers business. In the logistics conditions, there have been a variety of express logistics company stationed Qingyan Liu from 2007 onwards. By 2015, 5 logistics, the leading enterprises in the domestic courier as well as more than 20 foreign well-known courier logistics company including DHL Qingyan Liu has been stationed in Qingyan Liu, quickly and efficiently shipping the goods to all parts of the country even to more than 100 countries all around world. To deal with cargo concentration and the large quantities in Qingyan Liu, the express logistics companies design a special price system for it to enable Qingyan Liu to occupy a greater competitive advantage in the logistics express price. In addition, Jiangdong freight market, the largest logistics market in Yiwu City, is only one street apart from Qingyan Liu Village, greatly reducing the distance of its logistics and transportation.

Network goods rich in resources

As we all know, Yiwu, as the world's largest small commodity city, occupy 5.5 million square meters of small commodity market including more than 180 million kinds of goods that export to more than 210 countries and regions with the total annual turnover over 300 billion yuan. It's estimated that the country owes at least $75 \%$ of the net goods directly or indirectly to the Yiwu market. Rich net goods resources is a great support for e-commerce and also the natural advantages of Qingyan Liu model.

\section{A strong entrepreneurial atmosphere}

Industrial agglomeration, coupled with the formation of the ecological circle, enables Qingyan Liu to be the business community, attracting not only the villagers entrepreneurs of no capital and resource advantages, but also many traditional industry business owners, thus gathering a large 
number of entrepreneurial communities organization. Yiwu Business School started Taobao entrepreneurial class has become the first batch of electric business entrepreneurial groups of Qingyan Liu in 2009 and also the first college to start such courses. It's followed by that nearly ten thousand students start business in the Green Rock Liu. Students have entrepreneurial needs while Qingyan Liu village have talent needs, both form a complementary, opening new paths for employment growth. Therefore, Qingyan Liu promotes the industry to increase mobile electricity business by more than 20,000 people and the new platform electricity business by more than 2,000.

\section{Qingyan Liu model problems and countermeasures}

\section{Problems existing in the development of Qingyan Liu electricity business}

Although the Qingyan Liu model of rural e-commerce has developed rapidly and achieved great results,the model is not perfect. In fact, the model still has some urgent problems to be solved, which I summarizes as follows:

\section{Scale Problem}

The number of online shop under Qingyan Liu model has been topping, but the size of the shop is generally smaller. It's the case that it lacks sufficient funds to bear the relevant advertising and promotional costs. That's why they have difficulties in attracting more customers in a short period of time if for a wider range of visibility. In addition, the poor management quality, as well as the poor ability to withstand risk and participate in the market competition is also a drawback for shop with a small size.

\section{Product structure problem}

Qingyan Liu model has a large number of products, but the product quality varies greatly, some being low quality which seriously affects the future development. While Qingyan Liu village gradually forms a scale effect in its e-commerce development process, product homogeneity of the defects also arise[3]. At present, 50\% of network operators realize that homogeneous competition is the biggest obstacle to its business development. Even worse, long-term homogenization of competition will lead to price war and and a vicious circle that are not conducive to the healthy development of the industry[4].

\section{Talent issues}

As the electricity penetrates to rural areas, electric business talent gap is expanding while the rural electricity business develops rapidly. Many rural electricity business enterprises are subsequently weak after they have witnessed the initial high-speed growth. There are a lot of people whose business concept still remain in the original stage, that is, you can start a online shop as long as you are online[5], Whereas in the fierce electricity market competition, such business aspects as the product planning, quality standards, brand packaging, promotion and sales, logistics and after-sales must be clearly recognized in the management section even if for the relatively extensive rural electricity business, thus forming a larger demand for talent .

Warehousing problems

Qingyan Liu's houses are mostly residential structure, each room area about 36 square meters with a narrow space that is not conducive to storage, so it is difficult to meet the increasingly large demand for goods for the e-commerce, Qingyan Liu village cargo accumulation is not uncommon. As a result, e-commerce of a small scale have chosen to move away from Qingyan Liu.

\section{The response to the above problems}

\section{Reasonable expansion of the size of the online shop}

Network operators should carry out accurate market positioning and careful market research and investment planning in accordance with their own industry's characteristics to form a reasonable and orderly overall layout, collect their limited resources to expand the scale of electricity based on timely development needs, avoid blind expansion. In addition, internet business should enhance brand awareness as the brand is the store's intangible assets, the basis of exaggerated scale shop. Therefore, the operators should set up brand awareness, thereby enhancing the competitiveness of shops. 


\section{Innovation, differentiation of management}

Shop operators should improve the product's innovation ability, establish their own brand, and achieve the brand differentiation through brand positioning. The business operators of a scale can settle their shops in the well-known online trading platform or set up their own new brand to achieve product upgrades. In addition, when facing homogeneous products, they need to focus on innovation of marketing means, and conduct a unique rational layout modification for Taobao shop, improve the service quality either in pre-sales or after-sales.

Training and the introduction of electrical professionals

Personnel engaged in the relevant industry in Qingyan Liu village gets professional personnel training by combining Yiwu Business School and other university resources. Regularly invite experts in the field of e-commerce to do the relevant lectures, hold electric business forum,carry out electricity business salon, to create businessmen gatherings and exchange atmosphere in order to promote the exchange of professionals. The e-commerce professionals recruitment will be strengthened to improve the treatment of relevant personnel and pay attention to the company's exchange and cooperation with large-scale online trading platform.

Construction of intelligent storage system

The construction of network warehouses can take the form of tender by the logistics company to form intelligent warehousing, so as to achieve Qingyan Liu storage system optimization and upgrading. Compared with traditional logistics storage facilities, intelligent storage system can save labor cost, rent cost and improve management efficiency. In addition, the warehouse logistics park can be established to realize the integration of the warehouse logistics in the Qingxi town.

Construction of industrial cluster advantages

The government and relevant departments should formulate corresponding industrial cluster protection policies and implement them. In addition, the key to enhance the advantages of industrial clusters lies in regional innovation capacity. In Qingyan Liu Village, a number of network operators are scattered and lack of characteristics, so they should continue to enhance innovation, to attract external advanced capital, technology, talent and other elements more and to create regional unique brand, thus forming a strong competitive advantage.

\section{Conclusion}

Qingyan Liu model has many advantages under the rapid development of rural electric business, but there are still such problems as size, product structure, talent, warehousing according to the above questions. The author has put forward the corresponding recommendations. Qingyan Liu model under the rural electricity business will continue to sound public entrepreneurship and innovation horn and become the the sample of national electricity commercial development and can be copied.

\section{References}

[1] Wen Jing. Qing Yanliu Mode to Promote the Development of Rural Electricity Industry, Agricultural Engineering Technology, 2016,(06):55-55.

[2] Yu Shanshan. Research on E-commerce in Yiwu Professional Market, Reading and writing (education and Teaching journal), 2012,(07):77-78.

[3] Zhou Xia. Analysis on the Harm of Homogeneity of Products and Its Countermeasures, Economy Study,2016,(06):14-14.

[4] Zhang Lulu, Shu Jianwu. An Analysis of the Current Situation of E-commerce Development in Zhejiang Province--A Case Study of Qing Yanliu village in Yiwu, Jiangsu Merchants, 2016,(20):87-88.

[5] Liu Yali, Zhang Mingxing. Internet Plus Agricultural Product: A probe into the Influence of Electric Brokers on Economic Development in the Field of Vision--A Case Study of Xiangxi state, Economic Horizons,2016,(07):69-70. 
[6] Caiyun, Yin Ronglin. Internet Plus Agriculture: The Predicament and Breakthrough of Rural Electric Business Development--Based on the Investigation of Changxing County of Zhejiang Province, Economist, 2016,(08):58-59,61.

[7] Sun Boyang, Xia Xiaolun.The Gap of Rural E-commerce Talents Is Increasing Experts: Need for Supporting Policies, Economic information,2015,(09).

[8] Dong Mengyao. Research on the Financing Policy Support of SME Industry Cluster in Liaoning Province, Shen Yang University,2016.

[9] Mou Shaobo. Study on the sustainable growth mechanism of industrial clusters, Xinan Jiaotong University,2007.

[10]Xiong Xi. Study on the Formation Mechanism of Regional Industry Brand and Its Cultivation Strategy, Zhong Nan University,2013. 